\title{
Mapping family planning policy and programme best practices in the WHO Eastern Mediterranean Region: a step towards coordinated scale-up
}

\author{
P. Chikvaidze, ${ }^{\text {H H.H. Madi }}{ }^{2}$ and R.K. Mahaini ${ }^{3}$
}

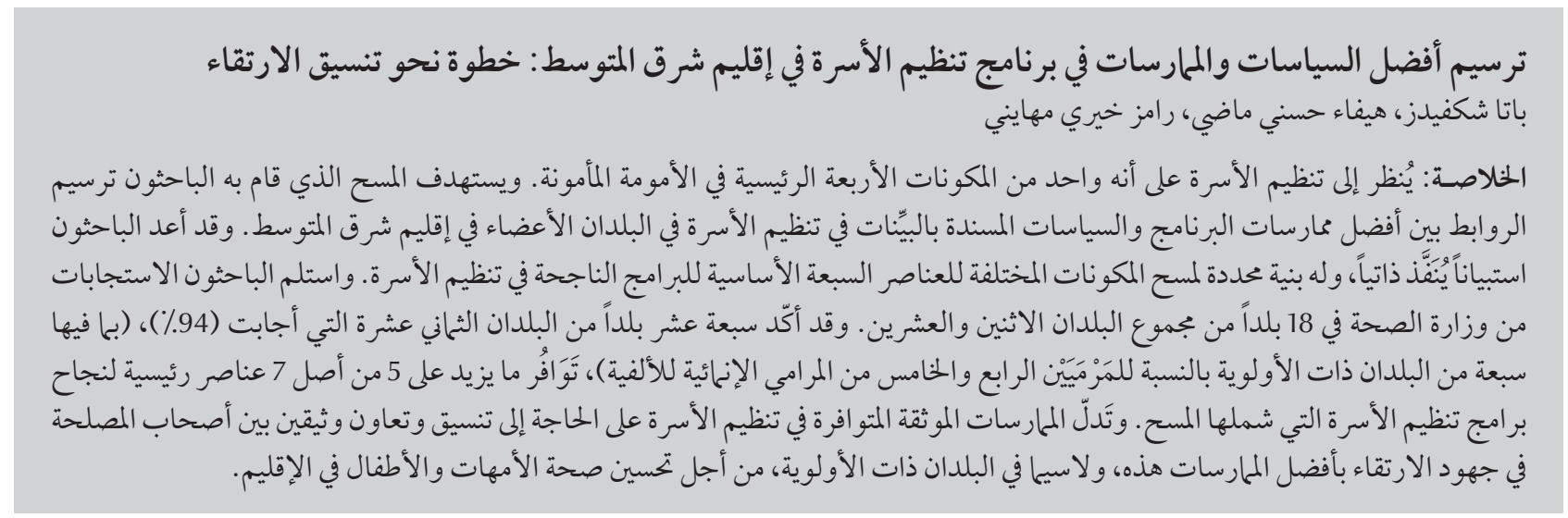

ABSTRACT Family planning is recognized as among the 4 core components of safe motherhood. This survey aimed to map evidence-based best policy and programme practices in family planning in the Member States of the WHO Eastern Mediterranean Region. A self-administered, structured questionnaire was developed to survey different components of 7 essential elements of successful family planning programmes. Responses were received from the ministry of health in 18 out of 22 Member States. A total of 17 out of 18 responding countries (94\%) (including 7 priority countries for Millennium Development Goals 4 and 5) confirmed the availability of at least 5 out of the 7 surveyed essential elements of successful family planning programmes. Documented available best practices in family planning suggest a need for close coordination and collaboration among stakeholders in scaling up these best practices, especially in priority countries, to improve maternal and child health in the Region.

Cartographie des meilleures pratiques dans la mise en oeuvre des politiques et des programmes de planification familiale dans la Région de la Méditerranée orientale : une étape vers un élargissement coordonné

RÉSUMÉ La planification familiale est reconnue comme faisant partie des quatre éléments indispensables d'une maternité à moindre risque. La présente enquête visait à cartographier les meilleures pratiques reposant sur une base factuelle pour la mise en oeuvre des politiques et des programmes de planification familiale dans les États Membres de la Région OMS de la Méditerranée orientale. Un questionnaire structuré et destiné à être autoadministré a été élaboré afin d'évaluer les différentes composantes de sept éléments essentiels dans un programme de planification familiale efficace. Des réponses ont été reçues du ministère de la Santé de 18 États Membres sur 22. Au total, 17 pays sur 18 ayant répondu (94\%) (les sept pays prioritaires pour les objectifs 4 et 5 du Millénaire pour le développement compris) ont confirmé la disponibilité d'au moins 5 éléments essentiels étudiés sur les 7 requis pour un programme de planification familiale efficace. Les meilleures pratiques documentées et disponibles en matière de planification familiale suggèrent qu'une coordination et une collaboration étroites sont nécessaires entre les parties prenantes dans l'élargissement de la mise en oeuvre de ces meilleures pratiques, en particulier dans les pays prioritaires, afin d'améliorer la santé des mères et des enfants dans la Région.

'Women's Reproductive Health; ${ }^{2}$ Health Protection and Promotion Division; ${ }^{2}$ Family and Community Health Unit, World Health Organization, Regional Office for the Eastern Mediterranean, Cairo, Egypt (Correspondence to P. Chikvaidze: chikvaidzep@emro.who.int).

Received: 28/07/10; accepted: 26/07/11 


\section{Introduction}

The World Health Organization (WHO) has estimated that in 2008 about 58300 women and 510000 newborns died in the countries of the Eastern Mediterranean Region (EMR) due to complications related to pregnancy and childbirth [1]. In order to achieve the United Nations Millennium Development Goals (MDG) 4A (reduce by two-thirds the under-5 mortality rate) and $5 \mathrm{~A}$ (reduce by three-quarters the maternal mortality ratio), between 1990 and 2015, policy-makers in EMR countries need to pursue the most effective, evidence-based strategies in health service delivery for improving maternal and child health outcomes [2].

Family planning (FP) is well recognized among 4 core components of safe motherhood, the other key health service strategies being: skilled attendance during pregnancy and childbirth; access to essential obstetric care; and postpartum care [3-5]. Promotion of FP to increase utilization of modern contraceptive methods, specifically in countries with high birth rates, has the potential to prevent up to $32 \%$ of all maternal deaths and almost $10 \%$ of childhood deaths, not to mention its indirect effects on promoting health through reducing poverty and hunger in overpopulated countries $[6,7]$. FP reduces mortality among women directly by avoiding the risk of death attributed to complications of childbearing and birth. However, it also indirectly reduces maternal mortality by shifting the risk associated with each pregnancy and birth away from high-risk maternal groups, e.g. among women who are too young (aged 1519 years [2]), older women (aged over 35 years [2]), multiparous women and women with existing health problems. In addition, achieving spacing of consecutive births by 2 years has been estimated to reduce the chance of dying in infancy or before the age of 5 years by up to $50 \%$ in developing countries $[3,8,9]$. In terms of financial benefits, it has been well demonstrated that investing in sexual and reproductive health, in particular FP, is cost-efficient for countries due to the substantial savings on costs related to health and social services and emotional distress to women, their family and society at large $[10,11]$.

Although progress has been made towards improving FP services in many countries of the EMR, the prevalence of use of modern contraceptives remains low. This is especially pertinent to 8 EMR countries where maternal mortality levels remain unacceptably high (Afghanistan, Djibouti, Iraq, Morocco, Pakistan, Somalia, Sudan and Yemen). These countries are classified as MDG priority countries due to poor performance in achieving targets of goals $4 \mathrm{~A}$ and $5 \mathrm{~A}$. In particular, Afghanistan, Pakistan and Sudan contribute up to $80 \%$ of the total annual maternal deaths in the EMR, while contraceptive prevalence rates for use of modern methods in these 3 countries are $17.4 \%, 21.7 \%$ and $5.7 \%$ respectively [1].

Achieving success in FP programmes requires continued, coordinated and harmonized efforts from different national and international concerned stakeholders. Yet significant amount of time and resources could be saved by documenting, sharing, adopting and scaling up successful practices in FP services, that could be classified as best practices in the Region. In addition, documentation of best practices in FP would advise international donor and national efforts in evidence-based policy decisionmaking, programming and scalingup. In the absence of any published literature on this subject in the Region we conducted this survey to identify and map evidence-based best policy and programme practices in FP in the countries of WHO EMR.

\section{Methods}

\section{Setting}

The survey was conducted in the 22 Member States of the WHO EMR: Afghanistan, Bahrain, Djibouti, Egypt, Islamic Republic of Iran, Iraq, Jordan, Kuwait, Lebanon, Libya, Morocco, Oman, Pakistan, Palestine, Qatar, Saudi Arabia, Somalia, Sudan, Syrian Arab Republic, Tunisia, United Arab Emirates and Yemen.

\section{Survey instrument}

A self-administered structured questionnaire was developed consisting of 77 questions that were grouped around 7 core categories widely recognized as essential components of successful FP programmes [12]. These were:

- integrated FP services and mix of service delivery points;

- staff training;

- polices, regulations and guidelines ensuring the quality of FP services;

- FP programmes targeted for special groups of population;

- FP commodity security;

- promotion of FP; and

- FP programme planning, monitoring and evaluation.

\section{Process}

The survey instrument was pretested in 4 EMR countries and finalized according to the feedback received. To standardize the survey process, the questionnaire was delivered to national FP programme managers through WHO representative offices and departments of international affairs at the ministries of health in each country. A supporting covering letter explained the purpose of the survey, type of the information being collected, description of who could answer the questions, where to return completed questionnaires and the voluntary nature of the survey. Reminder letters were sent to encourage responses from 
countries. Completed questionnaires were returned to the WHO Regional Office for the Eastern Mediterranean and examined for completeness. This process took place between May and August 2009.

\section{Analysis}

Descriptive statistics were used to analyse the data.

\section{Results}

Responses were received from 18 out of 22 Member States of WHO EMR. Of the 18 countries who responded to the survey 17 (94\%) confirmed the availability of at least 1 of the elements comprising 5 of the 7 essential components of successful FP programmes which we surveyed (Table 1).

\section{Integrated FP services and mix of service delivery points}

FP services were part of the basic health benefit package and were delivered at the primary health care level in 17 (94\%) of the 18 respondent countries (Table 2). At primary health care level, contraceptives were provided to all women free of charge in over threequarters of countries (78\%). A range of different types of contraceptives were part of the essential drug list in $89 \%$ of countries. Counselling about FP was provided at antenatal care visits in $89 \%$ and postnatal care visits in $94 \%$. While most countries provided actual FP methods postnatally (94\%), few provided them as part of antenatal care (22\%). FP counselling and methods were provided to parents as part of child care services in $61 \%$ of countries, vaccination services in 55\% and sexually transmitted infection/HIV services in $55 \%$.

Importantly, 7 of the MDGpriority countries in the region (Afghanistan, Iraq, Morocco, Pakistan, Somalia, Sudan and Yemen) reported the existence of many elements of best practices in terms of integrated FP services (Table 2) and other essential components of successful FP programmes, as reported in the following sections (Tables 3-8).

\section{Staff training}

FP was less commonly part of the preservice training programmes in medical universities ( $78 \%$ of countries) than through technical schools for midwives, nurses and lady health visitors (94\%) Table 3). However, FP was part of inservice continuing medical education for physicians in $94 \%$ and in-service training for midwives, nurses and lady health visitors in $83 \%$ of countries. FP training guidelines and materials were reportedly evidence-based in 83\% countries and were updated regularly in $72 \%$.

\section{Polices, regulations and guidelines ensuring the quality of FP services}

A competency-based national qualification system that certified health workers to provide FP counselling and services was in place in only onethird of respondent countries (Table 4). To ensure the safety of FP services, the national regulations required up-to-date minimum standards for health facilities in $89 \%$, medical equipment in $89 \%$, medical commodities in $100 \%$ and infection prevention measures in $94 \%$ of countries. The national guidelines and protocols for
FP counselling and service provision were reportedly evidence-based in $89 \%$ and regularly updated in $72 \%$ of countries. An effective and functional quality assurance system to ensure the quality of FP services provided was reported to be in place in half of countries. A supportive supervision system was in place to support service providers and improve their performance at primary health care level in $83 \%$ of countries and at secondary care level in 50\%.

\section{FP programmes targeted to special groups of population}

Less than half of responding countries had special FP programmes in place to meet the needs of certain vulnerable population groups: adolescents (39\%), internally displaced populations or refugees in $(50 \%)$, the poor $(50 \%)$, periurban and slum populations (44\%), males (22\%) and persons with disabilities (22\%) (Table 5).

\section{FP commodity security}

FP commodity security was reportedly ensured through: a well-functioning contraceptive logistics management information system (83\%), data-based planning by the government (61\%), effective supply chain management of all contraceptive commodities throughout the country $(67 \%)$ and in certain geographic areas of the country $(77 \%)$ (Table 6).

\begin{tabular}{lc}
\hline $\begin{array}{l}\text { Table } 1 \text { Number of essential components of successful family planning practices } \\
\text { present (defined as at least } 1 \text { element of the component present) in the family } \\
\text { planning programme of } \mathbf{1 8} \text { countries of the Eastern Mediterranean Region }\end{array}$ \\
\hline Country & $\begin{array}{c}\text { No. of essential } \\
\text { components present } \\
(\boldsymbol{n}=\mathbf{7})\end{array}$ \\
Afghanistan, Egypt, Iran (IR), Iraq, Jordan, Lebanon, \\
Morocco, Pakistan, Qatar, Syrian Arab Republic, Yemen \\
Oman, Palestine, Saudi Arabia, Sudan & 7 \\
Bahrain, Somalia & 6 \\
United Arab Emirates & 5 \\
Djibouti, Kuwait, Libya, Tunisia & 3 \\
\hline
\end{tabular}

$n / r=$ no response. 


\begin{tabular}{|c|c|c|c|c|c|c|c|c|c|}
\hline \multirow[t]{2}{*}{ Item } & \multicolumn{2}{|c|}{ All countries } & \multicolumn{7}{|c|}{ Priority countries $^{\mathrm{a}}$} \\
\hline & No. & $\%$ & Afg & Irq & Mor & Pak & Som & Sud & Yem \\
\hline $\begin{array}{l}\text { FP services are part of the basic health benefit package } \\
\text { and are delivered at the primary health care level }\end{array}$ & 17 & 94 & $\checkmark$ & $\checkmark$ & $\checkmark$ & $\checkmark$ & $\checkmark$ & $\checkmark$ & $\checkmark$ \\
\hline $\begin{array}{l}\text { At primary health care level, contraceptives are } \\
\text { provided to all women regardless of their ability to pay }\end{array}$ & 14 & 78 & $\checkmark$ & $\checkmark$ & $\checkmark$ & $\checkmark$ & $\checkmark$ & $\checkmark$ & $\checkmark$ \\
\hline $\begin{array}{l}\text { A mix of different types of contraceptives are part of } \\
\text { the country's essential drug list }\end{array}$ & 16 & 89 & $\checkmark$ & $\checkmark$ & $\checkmark$ & $\checkmark$ & $\checkmark$ & $\checkmark$ & $\checkmark$ \\
\hline \multicolumn{10}{|l|}{ FP counselling is provided: } \\
\hline At antenatal care visits & 4 & 22 & $\checkmark$ & $\checkmark$ & $\checkmark$ & $\checkmark$ & $\checkmark$ & $x$ & $\checkmark$ \\
\hline At postnatal care visits & 17 & 94 & $\checkmark$ & $\checkmark$ & $\checkmark$ & $\checkmark$ & $x$ & $\checkmark$ & $\checkmark$ \\
\hline \multicolumn{10}{|l|}{ FP methods are provided: } \\
\hline At antenatal care visits & 4 & 22 & $x$ & $x$ & $x$ & $\checkmark$ & $x$ & $x$ & $\checkmark$ \\
\hline At postnatal care visits & 17 & 94 & $\checkmark$ & $\checkmark$ & $\checkmark$ & $\checkmark$ & $\checkmark$ & $\checkmark$ & $\checkmark$ \\
\hline \multicolumn{10}{|l|}{$\begin{array}{l}\text { FP counselling and methods for parents are } \\
\text { provided during: }\end{array}$} \\
\hline Child health care services & 11 & 61 & $\checkmark$ & $x$ & $\checkmark$ & $\checkmark$ & $x$ & $x$ & $\checkmark$ \\
\hline Child vaccination services & 10 & 55 & $\checkmark$ & $x$ & $\checkmark$ & $\mathrm{n} / \mathrm{r}$ & $x$ & $x$ & $\checkmark$ \\
\hline STI/HIV services & 10 & 55 & $\checkmark$ & $\checkmark$ & $x$ & $\checkmark$ & $\checkmark$ & $x$ & $\checkmark$ \\
\hline \multicolumn{10}{|l|}{ FP counselling is provided by: } \\
\hline General practitioner/ family doctor & 16 & 89 & $x$ & $\checkmark$ & $\checkmark$ & $\checkmark$ & $\checkmark$ & $\checkmark$ & $\checkmark$ \\
\hline Obstetrician/gynaecologist & 17 & 94 & $\checkmark$ & $\checkmark$ & $\checkmark$ & $\checkmark$ & $\checkmark$ & $\checkmark$ & $\checkmark$ \\
\hline Nurse & 14 & 78 & $\checkmark$ & $\checkmark$ & $\checkmark$ & $\checkmark$ & $\checkmark$ & $x$ & $\checkmark$ \\
\hline Midwife & 14 & 78 & $\checkmark$ & $\checkmark$ & $\checkmark$ & $\checkmark$ & $\checkmark$ & $\checkmark$ & $\checkmark$ \\
\hline Community health worker & 10 & 55 & $\checkmark$ & $x$ & $\mathrm{n} / \mathrm{r}$ & $\checkmark$ & $\checkmark$ & $x$ & $\checkmark$ \\
\hline Lady health visitor & 11 & 61 & $\checkmark$ & $x$ & $\checkmark$ & $\checkmark$ & $x$ & $\checkmark$ & $\checkmark$ \\
\hline \multicolumn{10}{|l|}{ FP methods are provided by: } \\
\hline General practitioner/ family doctor & 18 & 100 & $\checkmark$ & $\checkmark$ & $\checkmark$ & $\checkmark$ & $\checkmark$ & $\checkmark$ & $\checkmark$ \\
\hline Obstetrician/gynaecologist & 18 & 100 & $\checkmark$ & $\checkmark$ & $\checkmark$ & $\checkmark$ & $\checkmark$ & $\checkmark$ & $\checkmark$ \\
\hline Nurse & 8 & 44 & $x$ & $x$ & $\checkmark$ & $\checkmark$ & $x$ & $x$ & $\checkmark$ \\
\hline Midwife & 12 & 67 & $\checkmark$ & $x$ & $\checkmark$ & $\checkmark$ & $x$ & $\checkmark$ & $\checkmark$ \\
\hline Community health worker & 8 & 44 & $\checkmark$ & $x$ & $\checkmark$ & $\checkmark$ & $x$ & $x$ & $\checkmark$ \\
\hline Lady health visitor & 9 & 50 & $\checkmark$ & $x$ & $\checkmark$ & $\checkmark$ & $x$ & $\checkmark$ & $\checkmark$ \\
\hline
\end{tabular}

${ }^{a}$ Afghanistan, Iraq, Morocco, Pakistan, Somalia, Sudan and Yemen: classified as priority countries due to poor performance in achieving targets of millennium development goals $4 A$ and $5 A$.

$\checkmark=$ available $; \mathbf{x}=$ not available $n / r=$ no response received from the country.

$S T I=$ sexually transmitted infection; HIV = human immunodeficiency virus.

\section{Promotion of FP}

FP was actively promoted in according to the respondent EMR countries through: effective social marketing of FP methods (67\%), via community education including wide distribution of quality education and information materials (77\%) and through community mobilization efforts (61\%). Public-private partnerships for FP were implemented more commonly via community education activities (77\%), but also via community outreach services (44\%) and service provision programmes $(44 \%)$ countries (Table 7 ).

\section{FP programme planning, monitoring and evaluation}

Decisions on changes in FP programme were made based on evidence and the analysis of information obtained from health management information systems (61\%), from FP programme evaluation (61\%) and from special national and sub-national studies (77\%) (Table 8). Evidencebased indicators were selected to monitor and evaluate FP programme $77 \%$ of countries. A similar proportion of countries $(72 \%)$ regularly collected and analysed FP programme data using health management information systems. 


\begin{tabular}{|c|c|c|c|c|c|c|c|c|c|}
\hline \multirow[t]{2}{*}{ Item } & \multicolumn{2}{|c|}{ All countries } & \multicolumn{7}{|c|}{ Priority countries $^{\mathrm{a}}$} \\
\hline & No. & $\%$ & Afg & Irq & Mor & Pak & Som & Sud & Yem \\
\hline \multicolumn{10}{|l|}{ FP is part of the pre-service training programmes: } \\
\hline In medical universities & 14 & 78 & $\checkmark$ & $x$ & $\checkmark$ & $\checkmark$ & $x$ & $\checkmark$ & $\checkmark$ \\
\hline $\begin{array}{l}\text { In technical schools for midwives, nurses and lady } \\
\text { health visitors }\end{array}$ & 17 & 94 & $\checkmark$ & $\checkmark$ & $\checkmark$ & $\checkmark$ & $\checkmark$ & $\checkmark$ & $\checkmark$ \\
\hline \multicolumn{10}{|l|}{ FP is part of in-service training programmes: } \\
\hline For continuing medical education for physicians & 17 & 94 & $\checkmark$ & $\checkmark$ & $\checkmark$ & $\checkmark$ & $\checkmark$ & $\checkmark$ & $\checkmark$ \\
\hline For midwives, nurses and lady health visitors & 15 & 83 & $\checkmark$ & $\checkmark$ & $\checkmark$ & $\checkmark$ & $\checkmark$ & $\checkmark$ & $\checkmark$ \\
\hline \multicolumn{10}{|l|}{ Training guidelines and materials are: } \\
\hline Evidence-based & 15 & 83 & $\checkmark$ & $\checkmark$ & $\checkmark$ & $\checkmark$ & $x$ & $\checkmark$ & $\checkmark$ \\
\hline Updated regularly & 13 & 72 & $\checkmark$ & $\checkmark$ & $\checkmark$ & $\checkmark$ & $x$ & $\checkmark$ & $\checkmark$ \\
\hline
\end{tabular}

${ }^{a}$ Afghanistan, Iraq, Morocco, Pakistan, Somalia, Sudan and Yemen: classified as priority countries due to poor performance in achieving targets of millennium development goals $4 A$ and $5 A$.

$\checkmark=$ available; $\mathbf{x}=$ not available.

\section{Discussion}

The major finding of this mapping survey is that all 18 respondent countries in the EMR have confirmed the existence of the majority of key elements of best policy and programme practices in FP. More than $90 \%$ of them had already taken actions and most of them have gained corresponding benefits through: integrating FP services into basic health benefit package at primary health care level and other vertical programmes; including a mix of different contraceptives into the national essential drug list; and by adopting evidence-based policies, guidelines, standards and practices for both health provider education and

Table 4 Polices, regulations and guidelines ensuring the quality of family planning (FP) services in all 18 respondent countries and the 7 priority countries of the Eastern Mediterranean Region, 2009

\begin{tabular}{|c|c|c|c|c|c|c|c|c|c|}
\hline \multirow[t]{2}{*}{ Item } & \multicolumn{2}{|c|}{ All countries } & \multicolumn{7}{|c|}{ Priority countries $^{\mathrm{a}}$} \\
\hline & No. & $\%$ & Afg & Irq & Mor & Pak & Som & Sud & Yem \\
\hline $\begin{array}{l}\text { A competency-based national quc } \\
\text { in place that certifies health work } \\
\text { FP counselling and services }\end{array}$ & 6 & 33 & $\checkmark$ & $\checkmark$ & $x$ & $\mathrm{n} / \mathrm{r}$ & $x$ & $x$ & $\checkmark$ \\
\hline \multicolumn{10}{|c|}{$\begin{array}{l}\text { To ensure the safety of FP services, national regulations } \\
\text { set up-to-date minimum standards for: }\end{array}$} \\
\hline Health facilities & 16 & 89 & $\checkmark$ & $\checkmark$ & $\checkmark$ & $\checkmark$ & $x$ & $\checkmark$ & $\checkmark$ \\
\hline Medical equipment & 16 & 89 & $\checkmark$ & $\checkmark$ & $\checkmark$ & $\checkmark$ & $x$ & $\checkmark$ & $\checkmark$ \\
\hline Medical commodities & 18 & 100 & $\checkmark$ & $\checkmark$ & $\checkmark$ & $\checkmark$ & $\checkmark$ & $\checkmark$ & $\checkmark$ \\
\hline Infection prevention measures & 17 & 94 & $\checkmark$ & $\checkmark$ & $\checkmark$ & $\checkmark$ & $\checkmark$ & $\checkmark$ & $\checkmark$ \\
\hline \multicolumn{10}{|c|}{$\begin{array}{l}\text { National guidelines and protocols for FP counselling } \\
\text { and service provision are: }\end{array}$} \\
\hline Evidence-based & 16 & 89 & $\checkmark$ & $\checkmark$ & $\checkmark$ & $\checkmark$ & $x$ & $\checkmark$ & $\checkmark$ \\
\hline Regularly updated & 13 & 72 & $\checkmark$ & $\checkmark$ & $\checkmark$ & $\checkmark$ & $x$ & $x$ & $\checkmark$ \\
\hline $\begin{array}{l}\text { An effective and functional qual } \\
\text { is in place to ensure the quality } \\
\text { services }\end{array}$ & 9 & 50 & $\checkmark$ & $x$ & $\checkmark$ & $\checkmark$ & $x$ & $x$ & $\checkmark$ \\
\hline \multicolumn{10}{|c|}{$\begin{array}{l}\text { Supportive supervision system is in place to support } \\
\text { service providers and improve their performance at: }\end{array}$} \\
\hline Primary health care level & 15 & 83 & $\checkmark$ & $\checkmark$ & $\checkmark$ & $\checkmark$ & $x$ & $\checkmark$ & $\checkmark$ \\
\hline Secondary health care level & 9 & 50 & $\checkmark$ & $\checkmark$ & $\checkmark$ & $\checkmark$ & $x$ & $\checkmark$ & $\checkmark$ \\
\hline
\end{tabular}

${ }^{a}$ Afghanistan, Iraq, Morocco, Pakistan, Somalia, Sudan and Yemen: classified as priority countries due to poor performance in achieving targets of millennium development goals $4 A$ and $5 A$.

$\checkmark=$ available; $\mathbf{x}=$ not available; $n / r=$ no response received from the country. 


\begin{tabular}{|c|c|c|c|c|c|c|c|c|c|}
\hline \multirow[t]{2}{*}{ Item } & \multicolumn{2}{|c|}{ All countries } & \multicolumn{7}{|c|}{ Priority countries $^{\mathrm{a}}$} \\
\hline & No. & $\%$ & Afg & Irq & Mor & Pak & Som & Sud & Yem \\
\hline \multicolumn{10}{|c|}{$\begin{array}{l}\text { Special programmes are in place designed to meet the } \\
\text { needs of vulnerable target groups: }\end{array}$} \\
\hline Adolescents & 7 & 39 & $x$ & $\checkmark$ & $x$ & $\mathrm{n} / \mathrm{r}$ & $x$ & $x$ & $\checkmark$ \\
\hline Internally displaced populations or refugees & 9 & 50 & $\checkmark$ & $x$ & $x$ & $\checkmark$ & $x$ & $\checkmark$ & $\checkmark$ \\
\hline Poor & 9 & 50 & $\checkmark$ & $x$ & $\checkmark$ & $\checkmark$ & $x$ & $x$ & $\checkmark$ \\
\hline Periurban and slum populations & 8 & 44 & $\checkmark$ & $x$ & $\checkmark$ & $\checkmark$ & $x$ & $x$ & $\checkmark$ \\
\hline Males & 4 & 22 & $\checkmark$ & $x$ & $x$ & $\mathrm{n} / \mathrm{r}$ & $x$ & $x$ & $\checkmark$ \\
\hline Persons with disabilities & 4 & 22 & $\checkmark$ & $x$ & $x$ & $\mathrm{n} / \mathrm{r}$ & $x$ & $x$ & $\checkmark$ \\
\hline
\end{tabular}

${ }^{a}$ Afghanistan, Iraq, Morocco, Pakistan, Somalia, Sudan and Yemen: classified as priority countries due to poor performance in achieving targets of millennium development goals 4 A and $5 A$.

$\checkmark=$ available; $\mathbf{x}=$ not available $n / r=$ no response received from the country.

service provision. Reportedly, about $60 \%$ of responded countries had reliable contraceptive logistics and supply chain management systems and implemented community education and outreach activities for FP services, including services for internally displaced and refugee communities where applicable.

The results also indicated certain deficiencies in the availability of evidence-based FP programmes in 18 responded countries. For example, only one-third of respondent countries paid adequate attention to FP service quality assurance through national certification and accreditation systems. In addition, few countries reported having FP programmes specially designed to address the needs of vulnerable population groups as adolescents, persons with disabilities, men and periurban populations.

There were several limitations to this survey. First, although the survey instrument was sent to ministries of health through WHO representative offices, we cannot be sure who completed the questionnaires and whether they were qualified to respond to the questions. Secondly, regardless of who completed the questionnaires, the survey was based on self-reporting and the results may therefore reflect over- or underreporting of services. Thirdly, responses came from only one source, the country's ministry of health, and we are not sure survey respondents had consulted other concerned organizations, such as universities, international and local partner organizations and professional associations. Another limitation of this survey was that it did not allow an evaluation of the geographical distribution of reported FP best practices, as well as their quality and sustainability.

The benefits of existing evidencebased practices do not always materialize into scaled-up national level programmes in the EMR. For example, in our survey the 4 largest contributor countries to maternal and under-5-yearold mortality in EMR - Pakistan, Afghanistan, Sudan and Yemen - reported meeting a high percentage of the 77 best practices surveyed (84\%, 94\%, $65 \%$ and $96 \%$ respectively). However,

Table 6 Commodity security in family planning (FP) services in all 18 respondent countries and the 7 priority countries of the Eastern Mediterranean Region, 2009

\begin{tabular}{|c|c|c|c|c|c|c|c|c|c|}
\hline \multirow[t]{2}{*}{ Item } & \multicolumn{2}{|c|}{ All countries } & \multicolumn{7}{|c|}{ Priority countries ${ }^{a}$} \\
\hline & No. & $\%$ & Afg & Irq & Mor & Pak & Som & Sud & Yem \\
\hline \multicolumn{10}{|l|}{ FP commodity security is ensured through: } \\
\hline $\begin{array}{l}\text { Well-functioning contraceptive logistics } \\
\text { management information system }\end{array}$ & 15 & 83 & $\checkmark$ & $\checkmark$ & $\checkmark$ & $\checkmark$ & $\checkmark$ & $x$ & $\checkmark$ \\
\hline Data-based planning by the government & 11 & 61 & $\checkmark$ & $x$ & $\checkmark$ & $\checkmark$ & $x$ & $x$ & $\checkmark$ \\
\hline $\begin{array}{l}\text { Effective supply chain management of all } \\
\text { contraceptive commodities throughout the country }\end{array}$ & 12 & 67 & $\checkmark$ & $x$ & $\checkmark$ & $\checkmark$ & $x$ & $x$ & $\checkmark$ \\
\hline $\begin{array}{l}\text { Effective supply chain management of all } \\
\text { contraceptive commodities in certain parts of the } \\
\text { country }\end{array}$ & 14 & 77 & $\mathrm{n} / \mathrm{r}$ & $\checkmark$ & $\mathrm{n} / \mathrm{r}$ & $\mathrm{n} / \mathrm{r}$ & $x$ & $x$ & $\mathrm{n} / \mathrm{r}$ \\
\hline
\end{tabular}

${ }^{a}$ Afghanistan, Iraq, Morocco, Pakistan, Somalia, Sudan and Yemen: classified as priority countries due to poor performance in achieving targets of millennium development goals $4 A$ and $5 A$.

$\checkmark=$ available; $\mathbf{x}=$ not available; $n / r=$ no response received from the country. 


\begin{tabular}{|c|c|c|c|c|c|c|c|c|c|}
\hline \multirow[t]{2}{*}{ Item } & \multicolumn{2}{|c|}{ All countries } & \multicolumn{7}{|c|}{ Priority countries $^{\mathrm{a}}$} \\
\hline & No. & $\%$ & Afg & Irq & Mor & Pak & Som & Sud & Yem \\
\hline \multicolumn{10}{|l|}{ FP is actively promoted through: } \\
\hline Effective social marketing of FP methods & 12 & 67 & $\checkmark$ & $\checkmark$ & $\checkmark$ & $\checkmark$ & $x$ & $\checkmark$ & $\checkmark$ \\
\hline $\begin{array}{l}\text { Community education, including wide distribution } \\
\text { of quality education and information materials }\end{array}$ & 14 & 78 & $\checkmark$ & $\checkmark$ & $\checkmark$ & $\checkmark$ & $x$ & $x$ & $\checkmark$ \\
\hline Community mobilization efforts & 11 & 61 & $\checkmark$ & $x$ & $\checkmark$ & $\checkmark$ & $\checkmark$ & $x$ & $\checkmark$ \\
\hline \multicolumn{10}{|l|}{ Public-private partnership is ensured in: } \\
\hline Community education activities & 14 & 78 & $\checkmark$ & $\checkmark$ & $\checkmark$ & $\checkmark$ & $x$ & $\checkmark$ & $\checkmark$ \\
\hline Community outreach services & 8 & 44 & $\checkmark$ & $\checkmark$ & $\mathrm{n} / \mathrm{r}$ & $\checkmark$ & $x$ & $x$ & $\checkmark$ \\
\hline Service provision programmes & 8 & 44 & $\checkmark$ & $x$ & $\mathrm{n} / \mathrm{r}$ & $\checkmark$ & $x$ & $\checkmark$ & $\checkmark$ \\
\hline
\end{tabular}

${ }^{a}$ Afghanistan, Iraq, Morocco, Pakistan, Somalia, Sudan and Yemen: classified as priority countries due to poor performance in achieving targets of millennium development goals $4 A$ and $5 A$.

$\checkmark=$ available; $\boldsymbol{x}=$ not available; $n / r=$ no response received from the country.

the contraceptive prevalence for use of modern methods in these countries is reported to be low $(16 \%, 22 \%, 6 \%$ and $13 \%$ respectively) [1]. This calls into question the scale and quality of implementation of acknowledged best practices in these countries. For instance, FP services may be included in basic health benefit packages at primary health care level and integrated into other vertical programmes such as child care or sexually transmitted infections/ HIV prevention, but not actually accessible to clients due to different reasons, such as deficiency in availability of qualified and/or motivated personnel, lack of contraceptive commodities or insufficient empowerment and social support to women. Similarly, although respondent countries widely acknowledged the existence of successful practices in FP programmes, according to 2008 estimates, on average only $31.1 \%$ of married women in EMR were using modern contraceptive methods to avoid unwanted pregnancy, which corresponds to a regional average total fertility rate as high as 4.2 children per woman of reproductive age (15 to 49 years) [13].

The results of our survey add to the scarce published literature on the availability of best FP policies and programmes in the EMR. Some countries, such as Egypt, Jordan, Kuwait, Islamic Republic of Iran, Libya, Palestine and Tunisia, are champions both in implementing successful FP programmes and in achieving favourable indicators for contraceptive prevalence and maternal and under- 5 child mortality rates. However, such achievements will be difficult to observe in the MDG-priority countries unless existing constraints in terms of political commitment and bottlenecks in health service systems are addressed simultaneously. In their global assessment of the health system and policy environment for maternal, newborn and children health, the Countdown working group on

Table 8 Programme monitoring and evaluation and planning of family planning (FP) services in all 18 respondent countries and the 7 priority countries of the Eastern Mediterranean Region, 2009

\begin{tabular}{|c|c|c|c|c|c|c|c|c|c|}
\hline \multirow[t]{2}{*}{ Item } & \multicolumn{2}{|c|}{ All countries } & \multicolumn{7}{|c|}{ Priority countries $^{\mathrm{a}}$} \\
\hline & No. & $\%$ & Afg & Irq & Mor & Pak & Som & Sud & Yem \\
\hline $\begin{array}{l}\text { Evidence-based indicators are selected to monitor and } \\
\text { evaluate FP programme }\end{array}$ & 14 & 78 & $\checkmark$ & $\checkmark$ & $\checkmark$ & $\checkmark$ & $x$ & $\checkmark$ & $\checkmark$ \\
\hline $\begin{array}{l}\text { Health management information system regularly } \\
\text { collects and analyses FP programme data }\end{array}$ & 13 & 72 & $\checkmark$ & $\checkmark$ & $\checkmark$ & $\checkmark$ & $x$ & $\checkmark$ & $\checkmark$ \\
\hline \multicolumn{10}{|l|}{$\begin{array}{l}\text { Decisions on changes in FP programme are made based } \\
\text { on the evidence and analysis of information obtained from: }\end{array}$} \\
\hline Health management information system & 11 & 61 & $\checkmark$ & $\checkmark$ & $\checkmark$ & $\mathrm{n} / \mathrm{r}$ & $x$ & $x$ & $\checkmark$ \\
\hline FP programme evaluation & 13 & 72 & $\checkmark$ & $\checkmark$ & $\checkmark$ & $\checkmark$ & $x$ & $x$ & $\checkmark$ \\
\hline Special national and subnational studies & 14 & 77 & $\checkmark$ & $\checkmark$ & $\checkmark$ & $\checkmark$ & $x$ & $\checkmark$ & $\checkmark$ \\
\hline
\end{tabular}

${ }^{a}$ Afghanistan, Iraq, Morocco, Pakistan, Somalia, Sudan and Yemen: classified as priority countries due to poor performance in achieving targets of millennium development goals $4 A$ and $5 A$.

$\checkmark=$ available; $\mathbf{x}=$ not available; $n / r=$ no response received from the country. 
policy and health systems suggested that the prerequisites for successful implementation and eventual scale-up of evidence-based practices are: strong national leadership and effective governance; adequate and sustainable financial resources; integration of desired services; and availability of qualified workforce [14].

In order to promote the diffusion of successful FP programmes during the past decade $\mathrm{WHO}$ and its partners have focused on identifying, documenting and categorizing successful policy and programme practices in FP. Recently 10 essential components of successful FP practices have been crystallized and shared widely [12]. In addition, the Implementing Best Practices consortium was established in 2003, sponsored by WHO, the United Nations Population Fund (UNFPA) and the United States Agency for International Development (USAID) and represented by more than 23 international agencies, to advance documentation and diffusion of knowledge about best practices to improve reproductive health outcomes [15]. Further, a special operations research methodology called "A guide for fostering change to scale up effective health services" was developed and promoted by WHO and USAID to facilitate the process of scaling-up successful reproductive health practices in countries [16].

It is important to mention that successful experience from countries where relevant operations research activities have been applied to increase contraceptive uptake and/or reduce maternal mortality have reported certain common factors that enabled success. These include: i) effective leadership and stewardship capacity of top national health authorities for coordination, collaborative planning and monitoring implementation of interventions; ii) a comprehensive approach in covering a range of key contributing factors, such as: policies, regulations and guidelines; health systems; health education and accreditation; health information and commodity security; iii) transparency and wide stakeholder involvement both from public and private sector; iv) continuous technical support and motivation of health organizations and personnel; and v) local capacity-building, close monitoring and supportive supervision [17-22]. Increasing the use of modern FP methods has a wide range of potential benefits including: improved maternal and child health; enhanced empowerment of women by reducing the burden of excessive childbearing; reduction of poverty; contribution to environmental sustainability; and significant monetary savings in reduced costs of health care, social welfare and environmental sustainability [23].

Additional research is needed to further elucidate the scale and quality of the existing best FP practices identified in individual countries of the WHO EMR. Countries lagging in achieving MDG goals $4 \mathrm{~A}$ and $5 \mathrm{~A}$ should invest both in scaling-up identified FP best practices, as well as adapting to the local context practices that have proved successful elsewhere in the Region. Priority should be given to scaling-up: integration of quality and acceptable FP counselling and methods into primary and community health care services; training and deployment of a sufficient skilled workforce; ensuring FP commodity security; and introducing performance motivation packages for qualified FP service providers.

In conclusion, the results of the study enable us to recommend that identified best policy and programme practices in family planning should: advise planning and implementation of FP programmes in the Region; and facilitate closer collaboration and coordination of efforts of stakeholders concerned to increase the prevalence of modern contraceptive use in order to improve maternal and child health in the countries of the WHO EMR.

\section{References}

1. The work of WHO in the Eastern Mediterranean Region. Annual report of the Regional Director. Cairo, World Health Organization, Regional Office for the Eastern Mediterranean, 2008.

2. Millennium Development Goals indicators. The official United Nations site for the MDG indicators. Untied Nations [online] (http://millenniumindicators.un.org/unsd/mdg/Host. aspx?Content=Indicators/OfficialList.htm, accessed 1 July 2012).

3. Health benefits of family planning. Geneva, World Health Organization, Unit of Family Planning and Population, Division of Reproductive Health, 1995.

4. Bullough $\mathrm{C}$ et al. Current strategies for the reduction of maternal mortality. International Journal of Obstetrics and Gynaecology, 2005, 112:1180-1188.

5. Bulatao RA, Ross JA. Which health services reduce maternal mortality? Evidence from ratings of maternal health services. Tropical Medicine and International Health, 2003, 8:710-721.
6. Cleland J et al. Family planning: the unfinished agenda. Lancet, 2006, 368:1810-1827.

7. Collumbien M, Gerressu M, Cleland J. Non-use and use of ineffective methods of contraception. In Ezzati M, et al., eds. Comparative quantification of health risks: global and regional burden of disease attributable to selected major risk factors. Geneva, World Health Organization, 2004:1255-1320 (NLM/ WA 105).

8. Ross JA, Blanc A. The contribution of family planning in reducing maternal mortality. Paper presented at the International Conference on Family Planning Research and Best Practices, Uganda, 15-18 November, 2009:210-211.

9. Huang W, Ronsmans C. Systemic review of childbearing patterns and maternal mortality. Paper presented at the International Conference on Family Planning Research and Best Practices, Uganda, 15-18 November, 2009:213-214. 
10. Singh S et al. Adding it up: the benefits of investing in sexual and reproductive health care. Geneva, United National Population Fund/The Allan Guttmacher Institute, 2004.

11. Mavranezouli I. Health economics of contraception. Best Practice and Research. Clinical Obstetrics and Gynaecology, 2009, 23:187-198.

12. Ten essential components of family planning programmes. Knowledge for health [online] (http://www.k4health.org/ topics/ten-elements-family-planning-success, accessed 15 July 2012).

13. Making pregnancy safer database. Cairo, World Health Organization Regional Office for the Eastern Mediterranean [online] (http://www.emro.who.int/mps/pdf/statistics_2008.pdf, accessed 1 July 2012).

14. Countdown Working Group on Health Policy and Health Systems. Assessment of the health system and policy environment as a critical complement to tracking intervention coverage for maternal, newborn, and child health. Lancet, 2008, 371:1284-1293.

15. The Implementing Best Practices (IBP) Initiative. Implementing best practices in reproductive health [online] (http://www. ibpinitiative.org/, accessed 15 July 2012).

16. Implementing Best Practices Consortium. A guide for fostering change to scale up effective health services. Geneva, World Health Organization/United States Agency for International Development, 2007.
17. Simons R, Fajas P, Ghiron L. Scaling up health service delivery: from pilot innovations to policies and programmes. Geneva, World Health Organization, 2007 (NLM/WA 550).

18. Solomon $\mathrm{M}$ et al. Creating a compendium of best practices: contributions of the IBP team. Paper presented at the International Conference on Family Planning Research and Best Practices, Uganda, 15-18 November, 2009: 308.

19. Bukusi VA et al. The success story of implementing best practice in Kenya. Paper presented at the International Conference on Family Planning Research and Best Practices, Uganda, 15-18 November, 2009: 224-225.

20. Hoemeke L et al. Repositioning family planning in Rwanda: how a taboo topic became a priority number one, and a success story. Paper presented at the International Conference on Family Planning Research and Best Practices, Uganda, 15-18 November, 2009:223-224.

21. Brambila $\mathrm{C}$ et al. Getting results used: evidence from reproductive health programmatic research in Guatemala. Health Policy and Planning, 2007, 22:234-245.

22. Ruiz-Rodríguez M, Wirtz VJ, Nigenda G. Organizational elements of health service related to a reduction in maternal mortality: the cases of Chile and Colombia. Health Policy, 2009, 90(2):149-155.

23. Cleland J. Contraception in historical and global perspective. Best Practice and Research. Clinical Obstetrics and Gynaecology, 2009, 23:165-176.

\section{Family planning: a global handbook for providers (2011 update)}

Family planning: a global handbook for providers (2011 update) is an essential resource for health-care professionals providing contraceptive methods. The handbook is the successor to The essentials of contraceptive technology, first published in 1997 by the Center for Communication Programs at Johns Hopkins Bloomberg School of Public Health. Experts from around the world have contributed to the development of the handbook, and many major international organizations and professional organizations working in family planning have endorsed and adopted this guidance. It is one of WHO's "Family Planning Cornerstones", a companion to the Medical eligibility criteria for contraceptive use, the Selected practice recommendations for contraceptive use and the Decision-making tool for family planning clients and providers.

This publication is also available in Arabic and French. Further information about this and other WHO publications is available at: http://www.who.int/publications/en/ 